\title{
Bactofection of SW620 cell by Lactococcus lactis M4
}

\author{
Habibah Faroque ${ }^{\mathrm{a}}$, Yi Siang Lau ${ }^{\mathrm{a}}$, Chee Xian Yonga ${ }^{\mathrm{a}}$, Raha Abdul Rahima, Suet Lin Chia ${ }^{\mathrm{b}, \mathrm{c}}$, Sarah \\ Othman ${ }^{a^{*}}$ \\ ${ }^{a}$ Department of Cell and Molecular Biology, Faculty of Biotechnology and Biomolecular Sciences, Unive rsiti Putra Malaysia, 43400 \\ UPM Serdang, Selangor, Malaysia \\ ${ }^{b}$ Department of Microbiology, Faculty of Biotechnology and Biomolecular Sciences, Universiti Putra Malaysia, 43400 UPM \\ Serdang, Selangor, Malaysia \\ 'Institute of Bioscience, Universiti Putra Malaysia, 43400 UPM Serdang, Selangor, Malaysia
}

Received 26th June 2018 / Accepted 27th August 2018

\begin{abstract}
In this study, a local dairy isolate, L. lactis M4 was investigated for its ability to be developed as a live delivery vector to deliver plasmid DNA into human colon cancer cell line, SW620. L. lactis M4 strain was found to adhere to and internalize SW620 cells optimally after 2 hours of infection period at a multiplicity of infection 250:1, bacteria per cancer cell. Bacteria also managed to survive intracellularly for 7 hours. Entry into SW620 cells was inhibited by Cytochalasin D and Vinblastine, indicating that cell uptake was dependent on microfilament and microtubule stability. Bactofection of SW620 cells by L. lactis M4 was demonstrated through the expression of fluorescent proteins from a novel dual-expression plasmid, pHSR. L. lactis M4 was able to express red fluorescent protein intracellularly of SW620 cells, which were subsequently observed to express green fluorescent protein at 3 hours post-invasion. The expression of fluorescent proteins from pHSR resulted from the bactofection of SW620 cells by L. lactis M4 has proven that this strain can be developed as a vector to deliver plasmid DNA into the cancer cell.
\end{abstract}

Keywords: live delivery vector, Lactococcus lactis M4, human colon cancer cell line, bactofection, gene delivery

\section{INTRODUCTION}

Lactic acid bacteria (LAB) have received gradual attention from scientists since the past decades as a tool for drug delivery and as targeting agents (Kochut and Dersch, 2013). The LAB family includes the genera Lactobacillus, Lactococcus, Streptococcus and many more (Stiles and Holzapfel, 1997). Generally, LAB are organisms of choice because they are Gram-positive microorganisms that lack lipopolysaccharide (LPS), an endotoxin that is present in Gram-negative bacteria. In addition, LAB could also survive in the strong acidic stomach environment when they are delivered orally. They undergo fermentation and produce lactic acid as an end-product (Sharma and Devi, 2014). For instance, Lactococcus strains are mainly used in the production of dairy products like cheese in European countries (Konings, 2000). Due to their certification as GRAS (Generally Recognized As Safe) organisms by the US Food and Drug Administration (FDA), the potential of LAB in several applications have been greatly enhanced. LAB have been reported to be utilized as cell factories for the expression of membrane proteins (Douillard et al., 2011), suppression of spoilage and growth of pathogenic bacteria (Jalilsood et al., 2015), production of

* Author for correspondence: Dr. Siti Sarah Othman, Senior Lecturer, Department of Cell and Molecular Biology, Faculty of Biotechnology and Biomolecular Sciences, Universiti Putra Malaysia, 43400 UPM Serdang, Selangor, Malaysia. Email - sarahothman@upm.edu.my 
biocatalyst (Hugenholtz et al., 2000) and delivery of therapeutic substances (Braat et al., 2006; Rottiers et al., 2009). It was suggested that, replacing the attenuated pathogenic bacteria as a delivery vector for therapeutic vaccine with $\mathrm{LAB}$ portrays a much safer alternative for cancer treatments (García-Fruitós, 2012).

Cancer is one of the leading causes of death in the world, accounting for almost 8.2 million of cancer-related deaths in 2012, whereby colorectal cancer alone has resulted in 694,000 deaths (Ferlay et al., 2012). Based on the report by National Cancer Institute (NCI), there are standard treatments available for cancer patients such as surgery, chemotherapy and radiation therapy. However, these treatments come with detrimental side-effects (American Cancer Society, 2013). Therefore, an alternative treatment such as gene therapy is anticipated. Recently, the first certified therapeutic cancer vaccine known as sipuleucel- $T$ (Provenge ${ }^{\circledR}$ ) was used to treat prostate cancer by eliciting an immune response against the antigens found on cancer cells (Kantoff et al., 2010).

Food grade bacteria such as LAB could be utilized as a delivery vector for DNA vaccination as they can be safely consumed. The internalized bacteria will be lysed and the plasmids will be released into the cytoplasm. Due to their small size, they somehow may escape the nuclease activity and get transferred into the nucleus, where transcription of genes will take place (Othman et al., 2013). Delivering plasmid DNA via bacteria cells also protects the naked DNA from degradation by nucleases and hence improves the efficacy of the delivery system (BermúdezHumarán et al., 2011; Kawabata et al., 1995; Lechardeur et al., 1999). Guimarães et al., (2006) has found out that the lactococci strain successfully enable the delivery of bovine $\beta$ lactoglobulin (BLG) cDNA into the mammalian epithelial cells. It was shown that the incubation of the cell line with naked DNA does not result in the transfer of the plasmid DNA unless it was contained by the bacterium host (Guimarães et al., 2006).

In this study, we would like to present a local isolate of L. lactis M4, originating from cow's milk, that is capable of not only delivering the DNA into the host cell but also enable the expression of reporter proteins in the colorectal cancer cell line,
SW620. A control strain, Lactobacillus reuteri CI 3.1.4 was included in the experiments conducted. This strain was isolated locally from the intestine of chicken in Agri-Biotechnology Institute, Malaysia and the 16S ribosomal RNA gene has been partially sequenced to further confirm on its identity. Since, L. lactis was known to be not as adherent as the Lactobacillus (Hanniffy et al., 2004; Di Cerbo et al., 2016; Nitisinprasert et al., 2006; A. Frese et al., 2012; Yagnik et al., 2016; Pontes et al., 2011), it is crucial to compare the ability of this locally isolated strain, L. lactis M4 and Lb. reuteri CI 3.1.4 to adhere and eventually get internalized into the human colon cancer cells.

\section{MATERIALS AND METHODS}

\section{Bacterial strains and growth conditions.}

Bacterial strains used in this study were: Lactococcus lactis M4 and Lactobacillus reuteri CI 3.1.4. L. lactis M4 was cultured using M17 media (Merck, Germany) supplemented with $0.5 \%$ glucose (GM17) and incubated at $30^{\circ} \mathrm{C}$ without aeration. The Lactobacillus strain was cultured using MRS media (Oxoid, UK) and incubated at $37^{\circ} \mathrm{C}$ in anaerobic condition.

Preparation of human colon cancer cell line, SW620. The SW620 [SW-620] (American Type Culture Collection ${ }^{\circledR}$ CCL-227 ${ }^{\mathrm{TM}}$ ) cell was grown as monolayer in DMEM (Nacalai, Japan) containing $1 \% \quad(\mathrm{v} / \mathrm{v})$ penicillin/streptomycin (Nacalai, Japan), 5\% (v/v) Fetal Bovine Serum (iDNA, Singapore) and incubated at 5\% (v/v) $\mathrm{CO}_{2}$ at $37^{\circ} \mathrm{C}$. SW620 cells from liquid nitrogen stock was cultured for three days before seeding into 24-well tissue culture plates at seeding density of $1 \times 10^{6}$ cells $/ \mathrm{ml}$ and incubated until monolayer is formed.

SW620 cell viability assessment. Trypan blue exclusion method was used to verify cell viability and cell count by using the Haemacytometer (Hirschmann ${ }^{\circledR}$ Laborgerate, Germany). Mixture of $10 \mu \mathrm{l}$ of $0.4 \%$ (w/v) Trypan blue (Sigma-Aldrich, USA) and $10 \mu \mathrm{l}$ of cell suspension was aliquoted and viewed using an inverted microscope with a 10X objective lens (Nikon, Japan). Non-viable cells appeared dark blue while viable cells appeared clear. 
Adhesion and invasion assay. Both of the interaction assays were performed in parallel, according to the protocol described by Othman, Parton, and Coote (2012), with few modifications. Bacterial strains were harvested from 16 hour cultures in GM17 and MRS broths and suspended in DMEM without antibiotics. The bacterial culture harvested was calculated according to an absorbance at $\mathrm{OD}_{600 \mathrm{~nm}}$ corresponding to the multiplicity of infection (MOI) tested. The bacterial suspension was added towards SW620 cells monolayer in 24-well tissue culture plates (SPL Biotech, Korea) for both adhesion and invasion assays. The plates were centrifuged at $600 \mathrm{x} g$ for 5 minutes to facilitate the bacteria to come in contact with the cell monolayer. The plates were then incubated at $37^{\circ} \mathrm{C}$ for 2 hours before washing with $1 \mathrm{X}$ Phosphate Buffered Saline (PBS, Vivantis, Malaysia). For adhesion assay, the SW620 cell monolayer was trypsinized with $0.5 \%(\mathrm{w} / \mathrm{v})$ trypsin-EDTA (Nacalai, Japan) and incubated at $37^{\circ} \mathrm{C}, 5 \%(\mathrm{v} / \mathrm{v}) \mathrm{CO}_{2}$ for 10 minutes. SW620 cells were then harvested and the wells were washed with $1 \mathrm{X}$ PBS until all the remaining cells were recovered. The cell suspension was then centrifuged at $600 \mathrm{x} g$ for 5 minutes and the pellet was washed in 1X PBS and centrifuged again to remove any remaining trypsin. The pellet was diluted in a millilitre of DMEM without antibiotics and an aliquot was removed for cell viability assessment using Trypan-blue. The remaining cells were lysed with $100 \mu \mathrm{g} / \mathrm{ml}$ of digitonin (Nacalai, Japan) and incubated for 30 minutes at $37^{\circ} \mathrm{C}$ and $5 \%(\mathrm{v} / \mathrm{v})$ $\mathrm{CO}_{2}$. The resulting lysate was labelled as the bacterial suspension. The bacterial suspension was serially diluted in $1 \mathrm{X}$ PBS before being plated onto two separate agar plates in duplicates and incubated overnight at $30^{\circ} \mathrm{C}$. Bacterial adhesion was calculated as mean number of bacteria per SW620 cell after incubation of bacteria with SW620 cells for 2 hours at selected multiplicity of infection (MOI) with duplicate samples. For the invasion assay, the steps were carried out according to the adhesion assay with an additional incubation step at 2 hours post-incubation. DMEM supplemented with $50 \mu \mathrm{g} / \mathrm{ml}$ of gentamicin (Nacalai, Japan) and kanamycin (Thermo Fisher Scientific, USA) was added into each well and incubated for another hour at $37^{\circ} \mathrm{C}$ and $5 \%(\mathrm{v} / \mathrm{v}) \quad \mathrm{CO}_{2}$ to remove extracellular bacteria. After that, the SW620 cell monolayers were washed gently with 1X PBS twice to remove any unattached extracellular bacteria. The method for cell viability assessment was carried out according to the adhesion assay. Finally, invasion is calculated as mean number of bacteria per SW620 cell that resist exposure to gentamicin and kanamycin, each at a final concentration of 50 $\mu \mathrm{g} / \mathrm{ml}$ for one hour after an infection period of 2 hours at selected MOI with duplicate samples.

Intracellular survival assay. This assay was performed according to the invasion assay with a prolong incubation step. After the antibiotic incubation step as in the invasion assay, the cell monolayer was washed twice with $1 \mathrm{X}$ PBS. The cell monolayer was then further incubated with several concentrations of antibiotics [kanamycin $(0-50 \mu \mathrm{g} / \mathrm{ml})$ and gentamycin $(0-50 \mu \mathrm{g} / \mathrm{ml})]$ up to 4 hours at $37^{\circ} \mathrm{C}, 5 \%(\mathrm{v} / \mathrm{v}) \mathrm{CO}_{2}$. Experimental wells without antibiotics added after the initial 3 hours incubation were included as standard experimental wells. In separate wells, prolonged incubation with the addition of $50 \mu \mathrm{g} / \mathrm{ml}$ of antibiotic was included as a measure to eliminate any remaining intracellular bacteria that could be released from the lysed SW620 cells during the incubation period. Lower concentration at 10 $\mu \mathrm{g} / \mathrm{ml}$ of antibiotic cocktail was included in another well as a measure to eliminate replication of any extracellular bacteria but with minimal possibility of entry into the cell and elimination of intracellular bacteria.

Invasion inhibition assay. The bacterial strains and SW620 cell were prepared according to the invasion assay. The monolayers were pre-treated for an hour with $0.25-0.5 \mu \mathrm{g} / \mathrm{ml}$ of Cytochalasin D (Sigma, USA) and Vinblastine (Sigma, USA) prior to the assay. The SW620 cell monolayers were then washed twice with 1X PBS before the addition of bacterial cells and continued with the standard protocol of invasion assay.

Construction of a dual-expression plasmid, pHSR. The DsRed monomer fragment was amplified using primers with internal EcoRI and XhoI sites (written in bold) (Forward: 5'GAAT'TCCCACCATGGACAACAC-3' and Reverse: 5'-CTCGAGCTACTGGGAGCCGGA 
GTG-3') from the plasmid pDsRed Monomer (Clontech, USA). This fragment was cloned into lactococcal plasmid pNZ8008 ${ }^{P} 170$, replacing the gusA gene fragment downstream of the autoinducible promoter, ${ }^{P} 170$ resulting in pNZRED ${ }^{P} 170$. Plasmid pEGFP-N1 (Clontech, USA) was digested using $X h o I$ and $K p n I$ restriction enzymes to remove the $S a l$ site from the multiple cloning sites, leaving the DNA fragment with sticky ends. The digested plasmid was analysed using agarose gel electrophoresis and the purified gel was used as template DNA in the extension PCR step using Pfu polymerase without the presence of primers. This step was performed to allow the addition of nucleotides to both restriction ends, forming a blunt-ended DNA fragment that allows self-ligation. This step was done in the PCR machine with the incubation at $72^{\circ} \mathrm{C}$ for 10 minutes. The product was then gel purified and self-ligated to produce plasmid pEGFP-M. The EGFP fragment was then amplified by $P f u$ polymerase from plasmid pEGFP-M using primers with internal Sall sites (written in bold) (Forward: 5'GTCGACATGGAGTTCCGCGTTAC-3' and Reverse: 5'-GTCGACTTCAATCATGCGAAA CGATCCTCATCC-3'). The amplified product was then ligated into the unique Sall site of the plasmid, pNZRED ${ }^{P} 170$, resulting in a dualexpression vector, pHSR. Ligation of these expression cassettes were executed at a ratio of 1:4 (plasmid:fragment). The plasmid transformation was performed by using MicroPulser ${ }^{\mathrm{TM}}$ (Bio-Rad, US) according to standard protocol (Holo and Nes, 1995). The positive transformants were screened on GM17 agar supplemented with $0.5 \mathrm{M}$ of sucrose and $10 \mu \mathrm{g} / \mathrm{ml}$ of chloramphenicol.

\section{Assessment of fluorescent protein expression from plasmid, pHSR. The expression of red} fluorescent protein (RFP) from plasmid, pHSR was assessed using microplate reader (Biotek, USA). Overnight bacterial culture was prepared as the standard procedure. $100 \mu \mathrm{l}$ of overnight culture was inoculated into $100 \mathrm{ml}$ of fresh GM17 broth. In order to test on the functionality of the promoter ${ }^{P} 170$, the bacterial culture was induced with different concentrations of DL-lactic acid (Amresco, USA) ranging from 0-300 $\mathrm{mM}$. About $2 \mathrm{ml}$ of sample was harvested at hourly intervals and washed in 1X PBS. $200 \mu \mathrm{l}$ of the cell suspension was aliquoted into 96-well flat bottom microplates, in triplicates. The absorbance readings of the samples were measured at $600 \mathrm{~nm}$ in a clear microplate, whereas the fluorescence intensity (FI) was measured at emission of $590 \mathrm{~nm}$ and excitation of $520 \mathrm{~nm}$ in a black bottom microplate. The readings obtained were compared with the bacterial sample without plasmid and $1 \mathrm{X}$ PBS as a control for background interference. A graph of FI against the concentration of lactic acid was plotted.

The expression of green fluorescent protein (GFP) was verified using the transient DNA transfection method of jetPRIME ${ }^{\circledR}$ DNA \& siRNA Transfection Reagent (PolyplusTransfection S.A., France), according to the manufacturer's protocol. About $8 \times 10^{5}$ cells $/ \mathrm{ml}$ of SW620 cell were seeded per well of a 24 -well cell culture plate 24 hours before transfection. A maximum recommended volume of DNA/jetPRIME ${ }^{\circledR}$ ratio 1:3 was chosen for the assay. The initial concentration of plasmid, pHSR used for the assay was $375 \mathrm{ng} / \mu \mathrm{l}$. The transfection medium was replaced with fresh complete growth medium after 4 hours of incubation. After 24 hours of incubation, the expression of GFP was viewed using the QImaging Retiga 6000 Monosystem (Olympus Life Science, Japan).

Plasmid stability test. The plasmid stability test was carried out according to Noreen et al. (2011) with minor modifications. About $100 \mu \mathrm{l}$ of overnight culture was inoculated into $100 \mathrm{ml}$ of fresh GM17 broth. The culture was sub-cultured into $100 \mathrm{ml}$ of fresh GM17 broth for every 8.5 hours. This is because at this time point, L. lactis M4 reached the late log phase and almost entering the stationary phase. This routine was repeated for 3 days until the generation time reaches more than 100 times. Plasmid pHSR was harvested at every subculture and analyzed by restriction enzyme digestion with $S a l \mathrm{I}$ for further confirmation. During the final sub-culture, serial dilution was performed and the culture was spread onto the GM17 agar plates with and without $10 \mu \mathrm{g} / \mathrm{ml}$ of chloramphenicol. The bacterial colonies formed on the GM17 agar plates without the antibiotic was sub-cultured onto GM17 agar with $10 \mu \mathrm{g} / \mathrm{ml}$ chloramphenicol. The ability of colonies to grow on the agar 
confirmed the presence and stability of pHSR in the L. lactis M4.

\section{Bactofection of SW620 cells by L. lactis M4 carrying a dual-expression plasmid, pHSR.}

This assay was performed in 4-wells glass bottom chamber slide (SPL, Korea) according to the invasion assay with additional steps. After the antibiotic incubation step, SW620 cell monolayer was further manipulated for visualization using Leica TCS SP5 confocal microscope system (Leica microsystem, Wetzlar, Germany).

\section{Fluorescent imaging on the interaction of $S W 620$ cells with $L$. lactis M4. The interaction} assay of SW620 cells with L. lactis M4 was carried out in a 4-wells chamber slides (SPL Biotech, Korea). After incubation with antibiotics, the cell monolayers were washed twice with 1X PBS. For live imaging, about $1 \mathrm{ml}$ of DMEM media was added into the chamber wells and prepared for viewing under Leica TCS SP5 confocal microscope system (Leica Microsystem, Wetzlar, Germany). However, for the preparation of the fixed sample imaging, about 4\% paraformaldehyde (Merck Millipore, USA) was added to each well and incubated for 20 minutes at $37^{\circ} \mathrm{C}, 5 \%(\mathrm{v} / \mathrm{v}) \mathrm{CO}_{2}$. Next, the solution was discarded and the fixed monolayers were washed twice with 1X PBS. HCS CellMask ${ }^{\mathrm{TM}}$ Stain (Invitrogen, USA) was added onto the fixed cells and incubated for 30 minutes at $37^{\circ} \mathrm{C}, 5 \%(\mathrm{v} / \mathrm{v})$ $\mathrm{CO}_{2}$. The solution was washed using $1 \mathrm{X}$ PBS and the wells were removed from the glass slide. ProLong Gold Antifade Mountant (Thermo Fisher Scientific, USA) were added at the side of the glass slide and gently pulled over to the other end of the surface by using a coverslip (HmbG, German). The mounting solution was ensured to evenly cover the whole surface of the fixed cells. A clean cover slip was then gently placed on top of the mounting medium, removing all the air bubbles in between and finally sealed with a crystal clear nail varnish. The slide was stored in the dark at upright position in a glass slide holder at $4^{\circ} \mathrm{C}$, until viewing with CLSM. The images obtained were analyzed and processed into threedimensional (3D) using the Leica Application Suite Advanced Fluorescence Lite (LAS AF) software. This software was utilized to model the bactofection in 3D and to produce sharper and clearer image by eliminating background interference. The images were taken using the 63X objective lens in 1.40 oil immersions under four different light exposures.

Data analysis. Mean, standard deviation and standard error of mean were calculated by applying student's t-test and tabulated by using Microsoft Excel.

\section{RESULTS}

A study on the cytotoxicity of L. lactis M4 towards SW620 cells was performed by using the trypan blue exclusion test. Any MOIs which were higher than 250:1, resulted in cell death (supplementary data). The MOI 250:1 and 100:1 bacteria per SW620 cell showed no significant difference in the percentage of SW620 cells viability and comparable to that of the control with a total cell viability of $90-95 \%$ (Supplementary Figure 1s). However, in order to increase the probability of bacteria to be in contact with cells during the interaction assays, a higher MOI of 250:1 was selected as the optimum MOI.

Using the optimized MOI of 250:1, the interaction rates for both of the LAB strains were investigated. The adherence rate of $L$. lactis M4 was significantly higher $(\mathrm{p}<0.05)$ compared to that of the control strain, $L b$. reuteri CI 3.1.4, a well-known natural colonizer (Dunne et al., 1999; Delgado et al., 2014; A. Frese et al., 2012) (Table 1). In the present study, L. lactis M4, without the presence of chemical treatment such as glycine, showed significantly higher number of intracellular bacteria compared to the treated $L$. lactis NZ3900 (Tao et al., 2011). The L. lactis M4 strain also showed significantly higher $(\mathrm{p}<0.05)$ internalization when compared to the control strain Lb. reuteri CI 3.1.4 (Table 1 ).

An intracellular survival assay was carried out in parallel with the standard invasion assay except that the antibiotic treatment was prolonged up to 7 hours. Different concentrations of kanamycin and gentamycin ranging from 0 to $50 \mu \mathrm{g} / \mathrm{ml}$ were included in each of the experimental wells. Based on the results shown in Table 2, the rate of invasion of $L$. lactis M4 significantly decreases as 
the time of incubation increases up to 7 hours. This suggested that the internalized bacterial strain were gradually eradicated by the SW620 cells. By comparing to the standard invasion assay, the rate of invasion obtained in prolonged incubation time does not show any difference between the different concentrations of antibiotics used indicating that extracellular bacteria has been successfully removed during the initial antibiotic treatment. However, different intracellular survival rate was observed at $5 \mathrm{~h}$ and $7 \mathrm{~h}$ between the wells without antibiotics and with 10 or $50 \mu \mathrm{g} / \mathrm{ml}$ antibiotics, indicating a possibility of uptake of the antibiotics intracellularly and elimination of the intracellular bacteria within the SW620 cells.

In order to understand the mode of entry of L. lactis M4 into the host, the SW620 cell monolayers were pre-treated with $0.25 \mu \mathrm{M}$ of Cytochalasin D and Vinblastine, (the microfilaments and microtubules destabilizers) for an hour prior to the invasion assay. Each drug showed sufficient inhibitory effects towards the entry of L. lactis M4 into the SW620 cells (Table $3)$. The invasion rate of $L$. lactis M4 towards pretreated SW620 cells was significantly decreased $(\mathrm{p}<0.05)$ as compared to the standard invasion rate.

Table 1. Adhesion and invasion rate of L. lactis M4 and Lb. reuteri CI 3.1.4 towards SW620 cells at MOI 250:1.

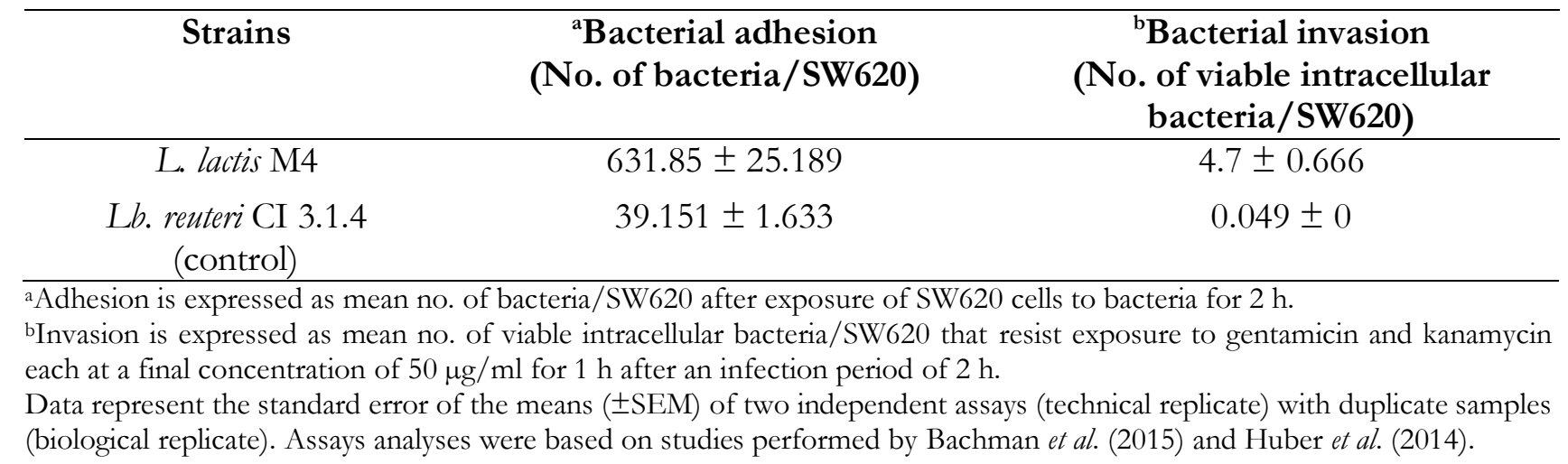

Table 2. Period of intracellular survival of L. lactis M4 in SW620 cells at MOI 250:1.

\begin{tabular}{ccccc}
\hline \multirow{2}{*}{$\begin{array}{c}\text { Invasion } \\
\text { time (hours) }\end{array}$} & $\begin{array}{c}\text { Standard invasion } \\
\text { assay }\end{array}$ & $\begin{array}{c}\text { Without addition } \\
\text { of antibiotic }\end{array}$ & $\begin{array}{c}\text { With addition of } \\
\text { K\&G } \mathbf{1 0} \boldsymbol{\mu g} / \mathbf{m l}\end{array}$ & $\begin{array}{c}\text { With addition of } \\
\text { K\&G } \mathbf{5 0} \mathbf{~} \mathbf{g} / \mathbf{m l}\end{array}$ \\
\hline 3 & $4.7 \pm 0.666$ & & & \\
$5(3+2)$ & & $0.271 \pm 0.110$ & $0.102 \pm 0.078$ & $0.068 \pm 0.032$ \\
$7(3+4)$ & & $0.282 \pm 0.219$ & $0.143 \pm 0.130$ & $0.029 \pm 0.018$ \\
\hline
\end{tabular}

anternalized viable bacteria was calculated as mean no. of bacteria/SW620 after incubation of $2 \mathrm{~h}$ followed by incubation with kanamycin and gentamicin $(K \& G)$ each at a final concentration of $50 \mu \mathrm{g} / \mathrm{ml}$ for an hour. Prolonged incubation for an additional of $2 \mathrm{~h}$ and $4 \mathrm{~h}$ was performed in the presence of $\mathrm{K} \& \mathrm{G}$ each at 0,10 and $50 \mu \mathrm{g} / \mathrm{ml}$. Data represent the standard error of the means ( \pm SEM) of two independent assays (technical replicate) with duplicate samples (biological replicate) (Bachman et al., 2015; Huber et al., 2014).

Table 3. Invasion inhibition of L. lactis M4 using Cytochalasin D and Vinblastine.

\begin{tabular}{ccc}
\hline $\begin{array}{c}\text { Pretreatment of SW620 } \\
\text { cells }\end{array}$ & $\begin{array}{c}\text { Percentage of viable SW620 } \\
\text { cells (\%) }\end{array}$ & $\begin{array}{c}\text { No. of viable intracellular } \\
\text { bacteria/SW620 }\end{array}$ \\
\hline Without treatment & 98 & $2.475 \pm 0.045$ \\
$0.25 \mu$ M Cytochalasin D & 96 & $0.044 \pm 0.015$ \\
$0.25 \mu$ M Vinblastine & 97 & $0.036 \pm 0.012$ \\
\hline
\end{tabular}

After treatment with the drugs, SW620 monolayers were washed twice with 1X PBS before continuing with the standard invasion assay (MOI 250:1). Data represent the standard error of the means ( \pm SEM) of three independent assays (technical replicate) with duplicate samples (biological replicate). 
In order to prove that L. lactis M4 could be used as a delivery vector to carry plasmid DNA into the mammalian cells, we constructed the dual-expression plasmid, pHSR by adapting the cloning strategy (Figure 1) of the 'traffic light' plasmid, pSRG by Othman et al. (2013). The plasmid contains both prokaryotic and eukaryotic expression cassettes carrying the red and green fluorescence proteins (RFP \& GFP) respectively. RFP expression was driven by an auto-inducible lactococcal promoter, ${ }^{P} 170$ whereas GFP expression was driven by the constitutive eukaryotic promoter of cytomegalovirus $\left({ }^{\mathrm{P}} \mathrm{CMV}_{\text {IE }}\right) \cdot \mathrm{pHSR}$ backbone consists of lactococcal replication genes, rep A and C, SV40 origin for propagation in mammalian cells, f1 origin for single-stranded DNA production and multiple cloning sites (MCS) for cloning.

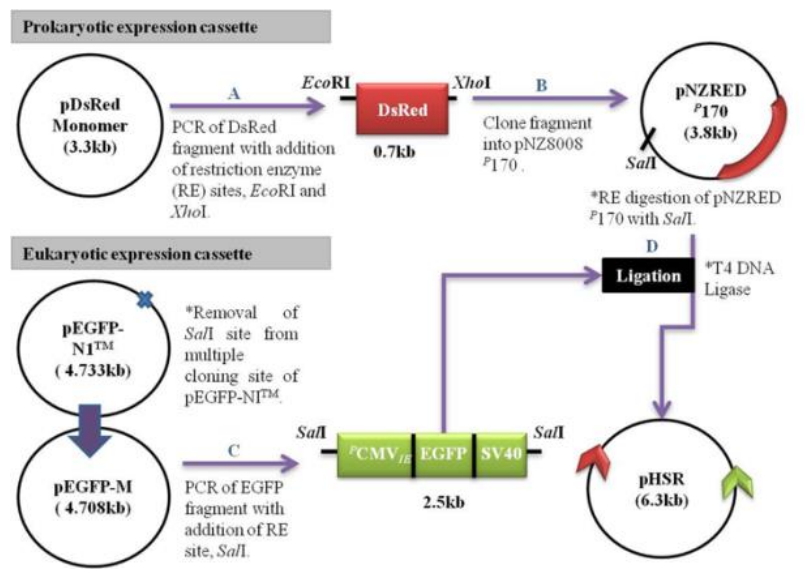

Figure 1. Cloning strategy of the dual-expression plasmid, pHSR. (A) Amplification of DsRed fragment from pDsRed Monomer. (B) Cloning of DsRed fragment into pNZ8008 ${ }^{P} 170$. (C) Amplification of EGFP fragment from pEGFPM. (D) Ligation of prokaryotic expression cassette with eukaryotic expression cassette resulting as plasmid, pHSR.

L. lactis M4 harbouring plasmid, pHSR was assessed for stability and about $90 \%$ of the transformants were able to grow on the agar plates. Expression of RFP by L. lactis M4 was assessed by measuring the fluorescent intensity (FI) using a microplate reader. Since the expression of the RFP via promoter ${ }^{P} 170$ is dependent on the environmental $\mathrm{pH}$, the promoter was induced with DL-lactic acid ranging from $0-300 \mathrm{mM}$ to verify on its functionality. The fluorescence intensity (FI) of the RFP expressed by $L$. lactis M4 during the late log phase $\left(\mathrm{OD}_{600 \mathrm{~nm}}\right.$ of 1.1) increases (Figure 2) as the concentration of lactic acid increases, confirming the functionality of the RFP cassette in the pHSR.

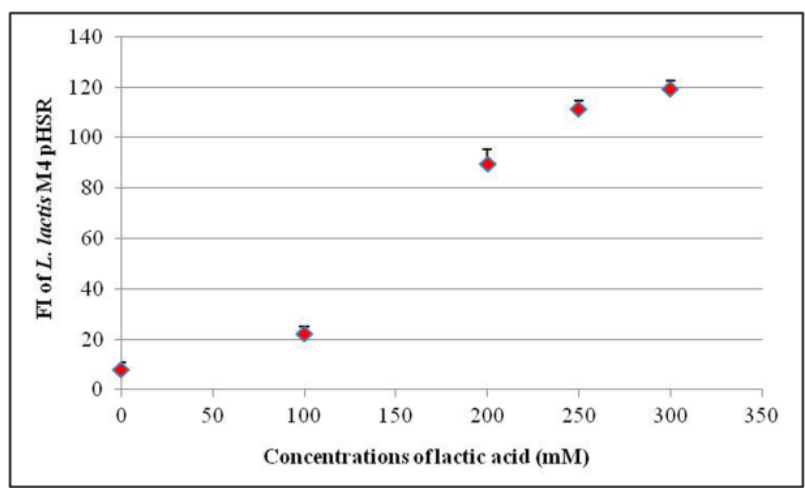

Figure 2. Graph of fluorescence intensity (FI) on RFP expression from L. lactis M4 pHSR against time at $\mathrm{OD}_{600 \mathrm{~nm}}$ of 1.1 . L. lactis $\mathrm{M} 4$ without plasmid was used as a control. Data were corrected for background fluorescence. Experiments were performed in triplicate and the error bars indicate standard error of the means ( \pm SEM).

In order to assess on the functionality of the eukaryotic expression cassette, pHSR was transfected into SW620 cells and analyzed after 24 hours of incubation (Figure 3). Images C and D were the transfected SW620 cells with pHSR showing that some of the cells started to emit GFP after 24 hours of incubation.

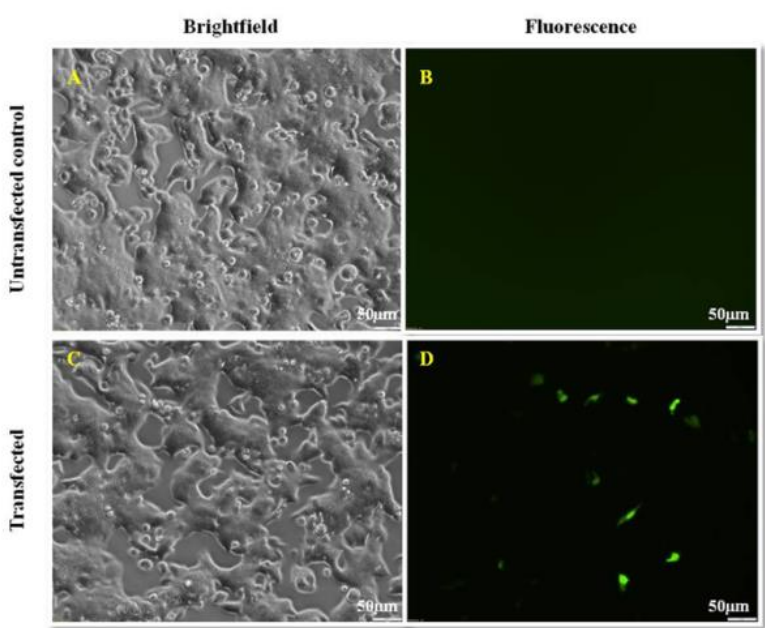

Figure 3. Images on GFP expression of SW620 cells after $24 \mathrm{~h}$ transfected with plasmid, pHSR. (A, C) Phase contrast images of SW620 monolayer; (B, D) Fluorescence images of SW620 
cell monolayer. Magnification at 20X. Excitation wavelength $=488 \mathrm{~nm}$, emission wavelength $=507$ $\mathrm{nm}$.

The bactofection system was completely modeled by observing the expression of fluorescence proteins from plasmid, pHSR. A set of the front view of the three-dimensional (3D) extended focus images during the bactofection of SW620 cells by L. lactis M4 pHSR was shown in Figure 4 . The $3 \mathrm{D}$ images were captured at 3 hours post-invasion at the same field on the slide. A single SW620 cell was captured under white light (Figure 4A) and under blue filtered fluorescent light (Figure 4B). The whole cell was counterstained with HCS CellMask ${ }^{\mathrm{TM}}$ Blue Stain. The overlay image of blue and red filtered fluorescent light showed the whole cell as blue and the internalized L. lactis M4 pHSR as red (Figure 4C). The last image is the overlay image of blue and green filtered fluorescent light showing the presence of GFP emitted by SW620 cell (Figure 4D). In addition to that, the functionality of CMV promoter was also checked in prokaryotic cells such as L. lactis M4 by viewing under the fluorescence microscope where it has negative result (data not shown).

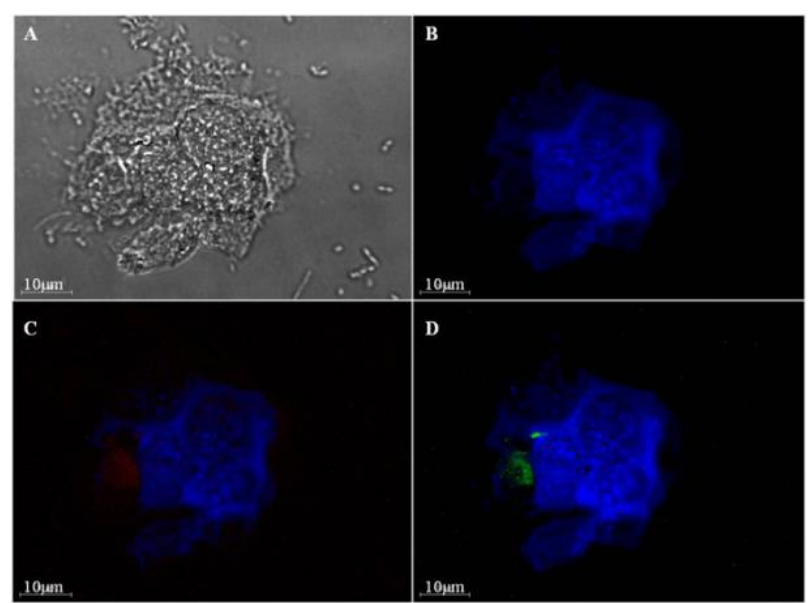

Figure 4. Confocal laser scanning microscopy extended focus images on RFP and GFP expressions during bactofection of SW620 cells by L. lactis M4 pHSR. Images were captured after 3 hours post-invasion. (A) SW620 cell was viewed under white light (B) front view of 3D image of $\mathrm{i}$ : by counterstaining with HCS CellMask ${ }^{\mathrm{TM}}$ Blue Stain (Thermo Fischer Scientific, USA), ii: image captured under filtered fluorescent light (415 nm$493 \mathrm{~nm})(\mathrm{C})$ Overlay front view of 3D image of i: image captured under filtered fluorescent light
(551 nm-703 nm) (red) to visualize the internalized RFP expressing L. lactis M4, (D) Overlay front view of 3D image of $\mathrm{i}$ : image captured under filtered fluorescent light $(498 \mathrm{~nm}$ $551 \mathrm{~nm}$ ) (green) to visualize expression of GFP by the SW620 cell. Magnification, $2 \times 63 \mathrm{x} / 1.40$ oil. Total exposures of 84 (4 channels, 21 frames).

Besides that, live imaging via CLSM during the bactofection process was performed in a different set of assay and visualized without any addition of counterstain. A set of Z-stack images arranged in increasing depth values (splicing at 41 frames and total stack depth of $-13.43 \mu \mathrm{m})$ as shown in Figure 5 was shown to localize GFP expression intracellularly of SW620 cells. As a negative control, the bactofection assay was performed on SW620 cells only. The SW620 cells were counterstained and analyzed using the same microscopy setting for Figures 4A-4D. It was observed that the whole cell was stained blue with no auto-fluorescence of RFP and GFP detected (data not shown).

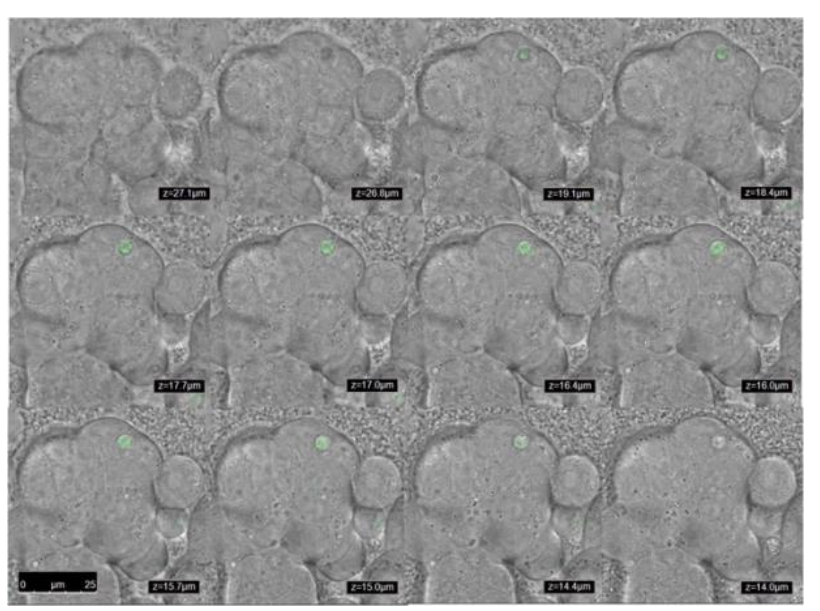

Figure 5. Confocal laser scanning microscopy zstack live images on GFP expressions during bactofection of SW620 cells by L. lactis M4 pHSR. Images obtained were optically sectioned for 41 times with depth of $-13.43 \mu \mathrm{m}$ and the image panels were arranged according to increasing of cell thickness. Magnification, $2.5 \times 63.0 x / 1.40$ oil.

\section{DISCUSSION}

Cell-bacterial interactions have been studied extensively over the decades. One of the most important study is the investigation of bacterial 
and host cells interaction on the mucosal layer in order to utilize bacteria as a live delivery vector for therapeutic DNA vaccine (Blanchette et al., 2009; Grangette et al., 2004). Recent studies have shown several added advantages in the manipulation of bactofection with lactic acid bacteria (LAB) such as having low production cost and does not involve further amplification and purification (Becker et al., 2008; Pálffy et al., 2006). LAB such as L. lactis has shown an efficient growth on chemically defined media and showed genetic integrity of bulk purified plasmid (Glenting and Wessels, 2005). These characteristics make L. lactis a sustainable and stable host in order to promote efficient DNA delivery into eukaryotic cells (Guimarães et al., 2006).

In this study, the growth characteristics of $\mathrm{LAB}$ strains such as $L$. lactis $\mathrm{M} 4$ and $L b$. reuteri $\mathrm{CI}$ 3.1.4 was studied. The log phases during the growth of both LAB strains were identified in order to quantify the amount of bacteria accurately for the preparation of bacterial culture according to the optimum multiplicity of infection (MOI). The bacteria were harvested during the log phase to ensure that they were mainly viable during the interaction assays. The doubling time of $L$. lactis M4 is faster compared to the Lb. reuteri CI 3.1.4 which is believed due to the colonizing nature of the Lactobacillus strain and their ability to sustain longer during each generation time (de Vos, 1999).

There were a few interaction studies reported to demonstrate the ability of the LAB strains to interact with epithelial intestinal cells such as Caco-2, T84 and HT29 cells (Rahman et al., 2014; Tao et al., 2011). Recent studies have also proven that commercial LAB strains, such as $L$. lactis NZ9000, Lb. delbrueckii and Streptococcus thermophilus were able to deliver fully functional plasmid into the mammalian cells in vitro and in vivo (Yagnik et al., 2016; Del Carmen et al., 2014). Some of these studies involve the introduction of treatments and invasive genes to increase the internalization rate for a better delivery process (Yagnik et al., 2017; Zurita-Turk et al., 2014; de Azevedo et al., 2012).

The interaction properties were analyzed through the adhesion, invasion and intracellular survival assays in order to determine the nature of bactofection between naturally derived $L$. lactis M4 with SW620 cells in comparison with a probiotic strain, $L b$. reuteri CI 3.1 .4 selected as the control. As shown above, Table 1 demonstrated L. lactis M4 ability to significantly adhere and invade the SW620 cells when compared to the control strain. The growth rate of $L$. lactis M4 strain is faster compared to $L b$. reuteri CI 3.1.4. $L$. lactis M4 strain within the two hours incubation with the presence of purine metabolites resulting from enhanced cell turnover in the tumor cells (Yu et al., 2008) and due to the presence of high concentration of glucose in the cell culture media which might escalate replication as observed in this study. It was also reported in a different LAB that Lb. bulgaricus managed to colonize tumors due to the leaky vasculature property within the tumor cells ( $\mathrm{Yu}$ et al., 2008) and serve as antitumor therapeutics of HPV-related cervical cancer (Bermudez-Humaran et al., 2005). In 2009, Collado et al. (2009) mentioned that the adhesive properties of $\mathrm{LAB}$, especially probiotics, towards epithelial cells were proven to be strongly influenced by the ability of the bacterial strains to auto-aggregate and also due to the cell surface hydrophobicity. Other study has also proven that $L$. lactis exhibit substantial adhesive properties (Kimoto et al., 1999). In addition, this strain was demonstrated to deliver functional plasmid in vitro and in vivo towards mammalian cells, albeit low gene transfer was observed (Chatel et al., 2008; Guimarães et al., 2006). Tao et al. (2011) reported that by using glycine to weaken the $L$. lactis NZ3900 cell wall, enhancement of bacterial cell uptake by Caco-2 cells was observed. However, no such treatment was needed for $L$. lactis M4 to efficiently adhere and internalise into the SW620 cells.

The intracellular survival assay aims to determine if there is any intracellular bacterial growth at various incubation periods. From the results obtained (Table 2) it was proven that the L. lactis M4 found within SW620 cells was eradicated from the cells over time. Similar observation was reported by Kamal et al. (2017), Othman et al. (2012), Galdiero et al. (2001), and Guimarães et al. (2009) with different strains of non-intracellular bacteria. These perhaps indicate the inability of this bacterium to escape the vacuoles and thus were lysed by lysosomal enzymes.

Cytochalasin D and Vinblastine were chosen to analyze the route of bacterial entry into 
mammalian cells in the invasion inhibition assay (Table 3). These drugs were selected based on the study conducted by Durrbach et al. (1996) whereby it was shown that the intracellular uptake of ligands such as tranferrin and $\alpha 2$ macroglobulin into the mouse hepatoma cell line BWTG3 was due to the formations of actin filaments and microtubules during the endocytosis process (Durrbach et al. 1996). Based on the results obtained (Table 3), it could be deduced that the mode of entry for $L$. lactis M4 into SW620 cells involves both the microfilaments and microtubules assembly, which are required in the process of endocytosis. This observation is in line with the finding by Durrbach et al. (1996) and several other studies in regards with bacteria mode of delivery intracellularly of the mammalian cell lines (Galdiero et al., 2001; Othman et al., 2012; Vromman et al., 2014).

A dual-expression plasmid, pHSR was constructed to visualize the translocation of $L$. lactis M4 from the extracellular environment into the intracellular compartment of SW620 cells. L. lactis M4 harbouring the plasmid, pHSR was proven to be stable for 131 generation time in three days at 35 minutes per generation. Plasmid pHSR was designed with RFP within the prokaryotic expression cassette and green fluorescent protein GFP within the eukaryotic expression cassette. The availability of cloning sites upstream and downstream of the Dsred monomer gene as well as upstream of EGFP would allow for future insertion of any gene including therapeutic genes for cancer immunotherapy. The functionality of each expression cassette was assessed based on the expression of the reporter proteins. RFP expression from pHSR was induced by using different concentrations of lactic acid. Results obtained showed an increment in the fluorescent intensities (measured in RFU) as the concentration of lactate increases (Figure 3). This has proven that promoter, ${ }^{P} 170$ is working well in regulating the expression of RFP. The RFP expression under the control of ${ }^{P} 170$ promoter also allows tracking of the presence of cancerous cells since the microenvironment of these cells would be acidic due to the presence of lactate (Kato et al., 2013). This natural and resilient (Bredmose et al., 2001) auto-induced promoter would allow production of therapeutic genes without the addition of external inducer (CanoGarrido et al., 2015; Madsen and Vrang, 2006; Tao et al., 2011; Bermúdez-Humarán et al., 2011). The expression of GFP by SW620 cells was observed to be visible after 24 hours post-transfection with pHSR. The observation was made at 24 hours as suggested by the manufacturer. Images $\mathrm{A}$ and $\mathrm{B}$ (Figure 3) were the control for the experiment verifying that the SW620 cells do not autofluoresce under the fluorescent light. Image B showed the presence of strong green background which was due to high exposure of the filtered fluorescent green light towards the experimental well B to identify any false positive result. It was observed in other studies that cloning of gene into the eukaryotic expression plasmids enabled a single expression by the mammalian cells after intracellular delivery by using either invasive or non-invasive $L$. lactis strains (Guimarães et al., 2005; de Azevedo et al., 2012; Zurita-Turk et al., 2014; Yagnik, Padh and Desai, 2016; Yagnik et al., 2017). In this study, pHSR enable tracking of the internalization process of L. lactis M4 with SW620 cells by tracking the expressed reporter proteins in the bacteria (RFP) and in the mammalian cells (GFP).

The bactofection of SW620 cells was demonstrated at $3 \mathrm{~h}$ post-invasion (Figure 4 ) by the presence of GFP from the SW620 cells and RFP from the bacterial cells. These indicate that some of the internalized bacteria had been lysed and plasmid, pHSR was released into the intracellular environment of the SW620 cell to enable eukaryotic expression of GFP. The presence of intracellular bacteria expressing RFP at the same time in SW620 cell might indicate that some of the L. lactis M4 pHSR were still intact and the plasmid, pHSR had not yet been released. The images obtained (Figure 4C and 4D) provided substantial evidence that $L$. lactis M4 can express RFP from pHSR intracellularly when viable and deliver pHSR into the SW620 cells, which allows the tracking of bacteria as well as the plasmid location. To further confirm that the GFP expression comes within the SW620 cells, an optical splicing of cells was performed as shown in Figure 5. The $z$ - stack images obtained further confirmed the transfer of pHSR from the bacteria to the eukaryotic cells since the fluorescent intensity increases when the splicing (image 19.1 
$\mu \mathrm{m}-16.0 \mu \mathrm{m})$ were in the mid-section of the cells depth. Similar study conducted by Othman et al. (2013) has reported that they could detect the presence of RFP- expressing bacteria within the EBL cells at 3 hours post-infection, whereby at the same time, some of these EBL cells were found to be expressing GFP. The bactofection pathway involving SW620 cells might be similar as to what was reported and demonstrated by Othman et al. (2012, 2013), Yagnik et al. (2016, 2017) and Kamal et al. (2017) where the bacteria was localized into the vacuole upon internalization into the host cells. Previous interaction studies involving invasive bacteria such as Listeria monocytogenes or Shigella flexneri had reported that the internalized bacteria harboring the plasmid carrying the invasive gene manage to escape the vacuole into cytoplasm of host cell. The bacteria were soon lysed resulting in the release of the expression plasmid and somehow transferred into the nucleus where the invasive gene was expressed (Grangette et al., 2004; Guimarães et al., 2009; Durrbach et al., 1996; Vromman et al., 2014). In other studies involving L. lactis, it was hypothesized that after the internalization step, the bacteria cell was lysed inside the vacuole or phagosome before releasing the plasmid DNA where it was then transferred into the nucleus for gene expression (Yagnik et al. 2016). However, the detail mechanisms of plasmid transfer from the vacuole into the nucleus were never reported.

To conclude, plasmid, pHSR enabled the expression of RFP and GFP in the prokaryotic and eukaryotic cell systems separately. These advantages give novelty towards pHSR for having a dual-expression system as compared to other plasmids constructed for the bactofection study between the LAB and mammalian cells. Moreover, this study also demonstrated the bactofection by using a naturally derived local strain of $L$. lactis M4 to deliver a novel dual expression vector, pHSR into SW620 cells without the presence of any chemical enhancement or invasive proteins. This indicates that $L$. lactis M4 has the potential to be developed as a live vector to deliver plasmid DNA into mammalian cells. Further related studies have to be carried out in order to develop a stable bactofection system which utilizes $L$. lactis M4 to specifically target cancerous cells to enhance delivery. More evidence on the transfer of the plasmid DNA can be explored and established by utilizing various types of fluorescent protein dyes as optical markers for monitoring cellular processes in living system. For example, tracking dye such as Label IT $^{\circledR}$ Tracker ${ }^{\text {TM }}$ (Mirus Bio, USA) could be used for tracking plasmid DNA in the living cells. By applying this staining method, the process of intracellular DNA transfer can be unraveled as this has never been reported before. In addition, with this method, optimal dose dependent rate of bacteria per cell can be further investigated related to the amount of DNA transfer into the cell. This information will further enhance the efficiency of DNA delivery by this strain. In line with the development of a therapeutic DNA vaccination, the fluorescent genes in the plasmid, pHSR can be replaced with any available therapeutic genes for the treatment of colorectal cancer. It is a promising and a definitive platform for an improved immunotherapy treatment and recovery experience for cancer patients.

\section{ACKNOWLEDGEMENTS}

The authors would like to thank Ms Yuen Aoi Chee, the application specialist from Hi-Tech Instruments Sdn. Bhd. for providing assistance on the Leica TCS SP5 confocal microscope. Special thanks goes to Ms. Wan Nur Fadhilah and Mr. Loo Shu San for providing the reference strain, Lb. reuteri CI 3.1.4, used as control for the experiments. This study was funded by Universiti Putra Malaysia (GP-IPM/2013/9401700 and GPIPS/2014/9429500) and Ministry of Higher Education Malaysia (FRGS/2/2013/SG05/ $\mathrm{UPM} / 02 / 13)$.

\section{REFERENCES}

Frese S. A., Hutkins R. W., Walter J. (2012) Comparison of the colonization ability of autochthonous and allochthonous strains of lactobacilli in the human gastrointestinal tract. Advances in Microbiology 2(03):399.

American Cancer Society, 2013. Cancer Treatment. Cancer Treatment \& Survivorship Facts \& Figures, 44.

de Azevedo, M. et al. 2012. In vitro and in vivo characterization of DNA delivery using recombinant Lactococcus lactis 
expressing a mutated form of $L$. monocytogenes Internalin A. BMC Microbiology 12:299.

Bachman, M. et al. 2015. 5-Formylcytosine can be a stable DNA modification in mammals. Nature Chemical Biology 11(8):5557.

Becker, P. D., Noerder, M. \& Guzmán, C. A. 2008. Genetic immunization: bacteria as DNA vaccine delivery vehicles. Human Vaccines 4(3):189-202.

Bermudez-Humaran, L. G. et al. 2005. A novel mucosal vaccine based on live lactococci expressing E7 antigen and IL-12 induces systemic and mucosal immune responses and protects mice against human papillomavirus type 16induced tumors. Journal of Immunology 175(11):7297-7302.

Bermúdez-Humarán, L. G. et al. 2011. Lactococci and lactobacilli as mucosal delivery vectors for therapeutic proteins and DNA vaccines. Microbial Cell Factories 10(Suppl 1), p.S4.

Blanchette, C. D. et al. 2009. Decoupling internalization, acidification and phagosomal-endosomal/lysosomal fusion during phagocytosis of $\operatorname{Inl} A$ coated beads in epithelial cells. Plos One 4(6):e6056.

Braat, H. et al. 2006. A Phase I trial with transgenic bacteria expressing interleukin-10 in Crohn's Disease. Clinical Gastroenterology and Hepatology 4(6):754-759.

Bredmose, L. et al. 2001. Development of a heterologous gene expression system for use in Lactococcus lactis. In Recombinant Protein Production with Prokaryotic and Eukaryotic Cells. A Comparative View on Host Physiology. Springer, pp. 269-275.

Cano-Garrido, O., Seras-Franzoso, J. \& Garcia-Fruitós, E., 2015. Lactic acid bacteria: reviewing the potential of a promising delivery live vector for biomedical purposes. Microbial Cell Factories 14(1):137.

Chatel, J. M. et al. 2008. In vivo transfer of plasmid from foodgrade transiting lactococci to murine epithelial cells. Gene Therapy 15(16):1184-90.

Collado, M. C. et al. 2009. The impact of probiotic on gut health. Current Drug Metabolism 10(1):68-78.

Del Carmen, S. et al. 2014. Genetically engineered immunomodulatory Streptococcus thermophilus strains producing antioxidant enzymes exhibit enhanced antiinflammatory activities. Applied and Environmental Microbiology 80(3):869-77.

Di Cerbo, A. et al. 2016. Mechanisms and therapeutic effectiveness of lactobacilli. Journal of Clinical Pathology 69(3), pp.187-203.

Delgado, S. et al. 2014. Probiotic and technological properties of Lactobacillus spp. strains from the human stomach in the search for potential candidates against gastric microbial dysbiosis. Frontiers in Microbiology 5:766.

Douillard, F. P. et al. 2011. Expanding the molecular toolbox for Lactococcus lactis: construction of an inducible thioredoxin gene fusion expression system. Microbial Cell Factories 10:66.

Dunne, C., et al. 1999. Probiotics: from myth to reality. Demonstration of functionality in animal models of disease and in human clinical trials. In Lactic Acid Bacteria: Genetics, Metabolism and Applications (pp. 279-292). Springer, Dordrecht.

Durrbach, A., Louvard, D. \& Coudrier, E., 1996. Actin filaments facilitate two steps of endocytosis. Journal of Cell Science 109 (2):457-465.

Ferlay J., et al. 2012. Cancer Incidence and Mortality Worlwide. GLOBOCAN v1.0, p.IARC CancerBase No.11.

Galdiero, M. et al. 2001. Interactions between bovine endothelial cells and Pasteurella multocida: association and invasion. Research in Microbiology 152(1):57-65.

García-Fruitós, E. 2012. Lactic Acid Bacteria: a promising alternative for recombinant protein production. Microbial Cell Factories 11(1):157.

Glenting, J. \& Wessels, S., 2005. Ensuring safety of DNA vaccines. Microbial Cell Factories 4(1):26.
Grangette, C., Mu, H., Hols, P. \& Goudercourt, D., 2004. Enhanced mucosal delivery of antigen with cell wall mutants of lactic acid bacteria. Infection and Immunity 72(5):2731-2737.

Guimarães, V. D. et al. 2009. A new plasmid vector for DNA delivery using lactococci. Genetic $V$ accines and Therapy 7(1):4.

Guimarães, V. D. et al. 2005. Internalin-expressing Lactococcus lactis is able to invade small intestine of guinea pigs and deliver DNA into mammalian epithelial cells. Microbes and Infection 7(5-6):836-44.

Guimarães, V. D. et al. 2006. Use of native lactococci as vehicles for delivery of DNA into mammalian epithelial cells. Applied and Environmental Microbiology 72(11):7091-7.

Hanniffy, S. et al. 2004. Potential and opportunities for use of recombinant lactic acid bacteria in human health. Advances in Applied Microbiology 56:1-64.

Holo, H. \& Nes, I. F., 1995. Transformation of Lactococcus by Electroporation. In J. A. Nickoloff, ed. Electroporation Protocols for Microorganisms. Totowa, NJ: Humana Press, pp. 195-199.

Huber, K. V. M. et al. 2014. Stereospecific targeting of MTH1 by (S)-crizotinib as an anticancer strategy. Nature 508(7495):222-227.

Hugenholtz, J. et al. 2000. Lactococcus lactis as a Cell Factory for High-Level Diacetyl Production. Applied and Environmental Microbiology 66(9):4112-4114.

Jalilsood, T. et al. 2015. Inhibition of pathogenic and spoilage bacteria by a novel biofilm-forming Lactobacillus isolate: a potential host for the expression of heterologous proteins. Microbial Cell Factories 14(1):96.

Kamal N. M., Zamri-Saad M., Masarudin M. J., Othman S. 2017. Interaction between Pasteurella multocida B: 2 and its derivatives with bovine aortic endothelial cell (BAEC). BMC Veterinary Research 13(1):186.

Kantoff, P. W. et al. 2010. Sipuleucel-T immunotherapy for castration-resistant prostate cancer. The New England Journal of Medicine 363(5):411-422.

Kato, Y. et al. 2013. Acidic extracellular microenvironment and cancer. Cancer Cell International 13(1):89.

Kawabata, K., Takakura, Y. \& Hashida, M., 1995. The fate of plasmid DNA after intravenous injection in mice: involvement of scavenger receptors in its hepatic uptake. Pharmaceutical Research 12(6):825-830.

Kimoto, H. et al. 1999. Lactococci as probiotic strains: adhesion to human enterocyte-like Caco-2 cells and tolerance to low $\mathrm{pH}$ and bile. Letters in Applied Microbiology 29(5):313-316.

Kochut, A. \& Dersch, P., 2013. Bacterial invasion factors: Tools for crossing biological barriers and drug delivery? European Journal of Pharmaceutics and Biopharmaceutics 84(2):242-250.

Konings, W. 2000. Lactic acid bacteria: the bugs of the new millennium. Current Opinion in Microbiology 3(3):276-282.

Lechardeur, D. et al. 1999. Metabolic instability of plasmid DNA in the cytosol: a potential barrier to gene transfer. Gene Therapy 6(4):482-497.

Madsen, S. \& Vrang, A., 2006. A regulatory acceptable alternative to $E$. coli: high yield recombinant protein production using the Lactococcus lactis $P 170$ expression system combined with "reverse electro enhanced dialysis" (REED) for lactate control. Microbial Cell Factories 2:1-2.

Nitisinprasert, S. et al. 2006. In vitro adhesion assay of lactic acid bacteria, Escherichia coli and Salmonella sp. by microbiological and PCR methods. Songklanakarin Journal of Science and Technology 28(suppl. 1):99-106.

Noreen, N. et al. 2011. Lactococcus lactis M4, a potential host for the expression of heterologous proteins. Microbial Cell Factories 10(1):28.

Othman, S. et al. 2013. Use of a dual reporter plasmid to demonstrate bactofection with an attenuated $\operatorname{AroA}(-)$ 
derivative of Pasteurella multocida B:2. PloS One 8(8):e71524.

Othman, S., Parton, R. \& Coote, J., 2012. Interaction between mammalian cells and Pasteurella multocida B:2. Adherence, invasion and intracellular survival. Microbial Pathogenesis $52(6): 353-8$.

Pálffy, R. et al. 2006. Bacteria in gene therapy: bactofection versus alternative gene therapy. Gene Therapy 13(2):101-5.

Pontes, D. S. et al. 2011. Lactococcus lactis as a live vector: Heterologous protein production and DNA delivery systems. Protein Expression and Purification 79(2):165-175.

Rahman, A. et al. 2014. Adaptation of the lactic acid bacterium Carnobacterium maltaromaticum LMA 28 to the mammalian gastrointestinal tract: From survival in mice to interaction with human cells. International Dairy Journal 34(1):93-99.

Rottiers, P., De Smedt, T. \& Steidler, L., 2009. Modulation of gutassociated lymphoid tissue functions with genetically modified Lactococcus lactis. International Reviews of Immunology 28(6):465-486.

Sharma, M. \& Devi, M., 2014. Probiotics: a comprehensive approach toward health foods. Critical reviews in food science and nutrition 54(4):537-52.

Stiles, M. E. \& Holzapfel, W. H., 1997. Lactic acid bacteria of foods and their current taxonomy. International Journal of Food Microbiology 36(1):1-29.

Tao, L. et al. 2011. A novel plasmid for delivering genes into mammalian cells with noninvasive food and commensal lactic acid bacteria. Plasmid 65(1):8-14.

de Vos, W. M. 1999. Gene expression systems for lactic acid bacteria. Current opinion in Microbiology 2(3):289-95.

Vromman, F. et al. 2014. Quantitative monitoring of the Cblamydia trachomatis developmental cycle using GFP-expressing bacteria, microscopy and flow cytometry. PLoS One, 9(6):e99197.

Yagnik, B. et al. 2017. Dual recombinant Lactococcus lactis for enhanced delivery of DNA vaccine reporter plasmid pPERDBY. Microbiology and Immunology 61(34):123-129.

Yagnik, B., Padh, H. \& Desai, P., 2016. Construction of a new shuttle vector for DNA delivery into mammalian cells using non-invasive Lactococcus lactis. Microbes and Infection 18:237244.

Yu, Y. A., Zhang, Q. \& Szalay, A. A., 2008. Establishment and characterization of conditions required for tumor colonization by intravenously delivered bacteria. Biotechnology and Bioengineering 100(3):567-578.

Zurita-Turk, M. et al. 2014. Lactococcus lactis carrying the pValac DNA expression vector coding for IL-10 reduces inflammation in a murine model of experimental colitis. BMC Biotechnology 14(1):73. 